\title{
Strategy towards enhanced performance of zeolite catalysts: raising effective diffusion coefficient versus reducing diffusion length
}

\author{
Peng Peng ${ }^{a, b}$, Dusan Stosic ${ }^{b}$, Xin-Mei Liu ${ }^{a}$, Zi-Feng Yan ${ }^{a} *$ Svetlana Mintova ${ }^{a, b} *$ \\ a State Key Laboratory of Heavy Oil Processing, China University of Petroleum, Qingdao 266580, China \\ ๖ Laboratoire Catalyse et Spectrochimie (LCS), Normandie Univ, ENSICAEN, UNICAEN, CNRS, \\ 14000 Caen, France \\ *Corresponding authors: E-mail address: svetlana.mintova@ensicaen.fr and zfyancat@upc.edu.cn
}

\begin{abstract}
In the present study, two strategies for improving the catalyst efficiency either by (1) raising the effective diffusion coefficient or (2) reducing the diffusion length of zeolite catalysts are presented. These two strategies are exemplified by the preparation of (i) ordered mesoporous material with zeotype secondary building units and (ii) self-assembled nanosized zeolites. The textural properties, acidity, and the results from the cumene cracking show that the strength and amount of Brønsted acid sites of the mesoporous materials are inferior, due to their amorphous pore walls. Even though the lifespan of ordered mesoporous material with zeotype secondary building units during cumene cracking can be improved due to the effective diffusion coefficient enhancement, the strength and amount of Brønsted acid sites related to the reaction are not akin to conventional microporous zeolites. While the self-assembled nanosized zeolites with short diffusion length shows enhanced catalytic performance by diffusion controlled reactions.
\end{abstract}

Keywords: catalyst effectiveness; effective diffusion factor; diffusion length; zeolites 


\section{Introduction}

Zeolites are a class of microporous crystalline aluminosilicate materials with pores of molecular dimensions $(0.3-1.5 \mathrm{~nm})$ [1]. Zeolites are widely used in oil refinery, petrochemical manufacture, fine chemical producing and environmental catalysis [2]. Success of zeolite in many industrially important processes is based on the strong and tunable Brønsted acidity, small pore size, high internal surface area, flexible frameworks, adjustable and controlled chemistry and high thermal stability. In particular zeolites are known for exceptional catalytic performance due to selectivity control by pore confinement effects [3-5]. This concept is known as shape-selectivity and is crucial in the synthesis of refinery products and organic transformations $[6,7]$. However, the size of pores and cages of zeolites also impose important mass transfer limitations that have negative influence on activity, but can also affect selectivity and lifetime of the catalyst [8]. In the chemical engineering, a catalyst effectiveness $(\eta)$ is used to describe the degree of catalysts' utilization that is related to mass transport limitations [9]. Catalyst effectiveness can be generally improved by the utilization of the materials with wide pores and/or with short diffusion length.

A typical case is the fluid catalytic cracking (FCC), which is one of the most important and profitable processes in oil refining industry $[7,10]$. As an important component in FCC catalyst, ZSM-5 zeolite serves for raising propylene and high octane number of gasoline components due to its unique framework structure and surface properties. Unfortunately, catalytic cracking reaction is always accompanied with coking reactions, i.e. formation of highly condensed poly-aromatic carbonaceous residues (coke species) 
[11]. Because the kinetic diameters of these coke species are usually much larger than the aperture of ZSM-5 (0.55 nm) [12], they have to withstand strong diffusion resistance in the micropores $[8,13]$. Thus coke species can easily be accumulated within the microporous channels, causing the rapid deactivation of the zeolite [14]. Within the past decades, due to the quality deterioration of oil throughout the world, deactivation caused by coking reaction becomes even more series [15]. Integrating both meso- and micro- pores into one hierarchical zeolitic structure is an attainable way to alleviate diffusion limitations and extend the catalysis lifespan of the zeolite frameworks. For example, previous research had shown that in terms of FCC and related reactions, the ZSM-5 based hierarchical materials exhibited higher heavy oil conversion, higher light oil product yield, and lower coke yield than their conventional micronsized counterparts [16-19]. Nowadays fabricating of hierarchical structures has become an important topic of zeolites and porous material chemistry [20,21]. Various strategies for synthesizing hierarchical zeolitic structures such as dealumination [22], desilication [20,21], nanocrystallization [25,26], zeolitization [27,28], delamination [29], hard templating [30], soft templating [31,32], composites [33], recrystallization [34-36], etc. have been developed.

Although diverse strategies for hierarchical zeolites have been advanced, there is little research devoted to the improvement of catalyst efficiency of materials for diffusion-controlled catalytic reaction. In chemical reaction engineering, the descriptor for measuring effects of diffusion resistance on catalytic reactions is the catalyst effectiveness factor $(\eta)[9,37]$, which can be quantitatively analyzed by adopting 
Thiele modulus $(\phi)$. For a reaction that is in regime of diffusion control $(\eta<0.25), \phi$ is the reciprocal of $\eta$ and it is calculated by the following equation:

$$
\frac{1}{\eta}=\phi=L \sqrt{\frac{k_{\mathrm{v}}}{D_{\text {eff }}}}
$$

where $k_{\mathrm{v}}$ (intrinsic kinetic constant) is fixed for a given reaction, so the Thiele modulus can only be diminished by raising the $D_{\text {eff }}$ (effective diffusion coefficient) or by reducing the $L$ (diffusion length). Based on this criteria, all the strategies for preparing hierarchical zeolitic structure can be divided into two groups, depending on improvement of the catalyst' efficiency: (1) raising the effective diffusion coefficient and (2) reducing the diffusion length of zeolites (Scheme 1). In this work, these two groups are exampled by preparing two samples: (i) ordered mesoporous material with MFI secondary building units (SBU) and (ii) self-assembled nanosized ZSM-5. Their physicochemical properties, catalytic activity, selectivity and deactivation in cumene cracking reaction were evaluated and compared with a conventional micronsized ZSM-5 zeolite.

\section{Experimental Section}

\subsection{Preparation of zeolite catalysts}

The conventional micronsized ZSM-5 (Sample-I, $\mathrm{SiO}_{2}: \mathrm{Al}_{2} \mathrm{O}_{3}=25$ ) was purchased from Nankai Catalyst Company, and denoted as Sample-I. Ordered mesoporous material with MFI secondary building units (Sample-II) was prepared based on a synthesis method described elsewhere [38,39]. Typically, parent ZSM-5 was mixed with $\mathrm{NaOH}$ aqueous solution $(150 \mathrm{~mL}$ of $1.0 \mathrm{~mol} / \mathrm{L})$ at $353 \mathrm{~K}$ for 60 minutes. Afterwards, $4.5 \mathrm{~g}$ cetyl trimethyl ammonium bromide $(\mathrm{CTAB})$ and $60 \mathrm{~mL}$ water transparent filtrate were 
mixed and stirred at $353 \mathrm{~K}$ for another 30 minutes. Then the $\mathrm{pH}$ of the mixture was adjusted to be 10.5 by dilution with $\mathrm{H}_{2} \mathrm{SO}_{4}(2.0 \mathrm{~mol} / \mathrm{L})$. The mixture was transferred into a Teflon-lined stainless steel autoclave and treated in an oven at $383 \mathrm{~K}$ for 24 hours. The sample was filtrated, dried, and calcinated in a muffle furnace at $823 \mathrm{~K}$ for 6 hours. Self-assembled nanosized ZSM-5 (Sample-III) was prepared from a mixture with a molar composition: $25 \mathrm{SiO}_{2}: 0.227 \mathrm{Al}_{2} \mathrm{O}_{3}: 3.4(\mathrm{TPA})_{2} \mathrm{O}: 441 \mathrm{H}_{2} \mathrm{O}$. In a typical synthesis process: tetrapropylammonium hydroxide (TPAOH, $7.5 \mathrm{~mL}, 1.0 \mathrm{~mol} / \mathrm{L})$, water $(2.5$ $\mathrm{mL})$, and $\mathrm{Al}_{2}\left(\mathrm{SO}_{4}\right)_{3} \cdot 18 \mathrm{H}_{2} \mathrm{O}(0.162 \mathrm{~g})$ were mixed and stirred for 10 minutes. Afterwards, tetraethyl orthosilicate (TEOS, $6 \mathrm{~mL}, 98 \%$ ) was added and stirred at room temperature for 6 hours. Then the system was transferred into a stainless steel autoclave with a Teflon-lined container and heated in an oven at $453 \mathrm{~K}$ for 12 hours. After crystallization, the product was purified and dried. Finally, the as-synthesized sample was calcinated at $823 \mathrm{~K}$ for 6 hours.

\subsection{Characterization}

Powder X-ray diffraction (XRD) patterns were recorded by a PANalytical X'Pert PRO MPD diffractometer equipped with $\mathrm{Cu} \mathrm{K}_{\alpha}$ radiation $(40 \mathrm{kV}, 40 \mathrm{~mA}, \lambda=0.1541 \mathrm{~nm})$ in the $2 \theta$ ranges of $2-10.0^{\circ}$ (small-angle XRD patterns) and $5-60^{\circ}$ (wide-angle XRD patterns).

Nitrogen adsorption-desorption isotherms were collected on a Micromeritics ASAP2020 at $77 \mathrm{~K}$. Prior to analysis, samples were pretreated at $673 \mathrm{~K}$ under vacuum. The Brunauer-Emmett-Teller (BET) equation and the adsorption data collected at $p / p_{0}$ $=0.96$ were used for calculating the specific surface area $\left(S_{\mathrm{BET}}\right)$ and the total pore 
volume ( $\left.V_{\text {total }}\right)$, respectively. Besides, micropore volume $\left(V_{\text {micro }}\right)$ was calculated by t-plot method using the Harkins-Jura equation.

Transmission electron microscopy (TEM) images were obtained on a JEOL

JEM2100UHR instrument.

$\mathrm{NH}_{3}$-temperature programmed desorption $\left(\mathrm{NH}_{3}-\mathrm{TPD}\right)$ measurements were carried out to test the amount and strength of acid sites of the samples by a Micromeritics Auto 2920 chemical adsorption analyzer. Typically, $0.10 \mathrm{~g}$ of samples were heated in a quartz tube from room temperature to $973 \mathrm{~K}$ under helium flow with temperature ramp of $10 \mathrm{~K} / \mathrm{min}$. The samples were then cooled to $373 \mathrm{~K}$, and ammonia was adsorbed for 30 minutes from an ammonia-helium mixture with a molar ratio of 1:9. The samples were flushed under helium for another 30 minutes to remove the gas phase and/or physically adsorbed $\mathrm{NH}_{3}$. TPD profile of ammonia was obtained from $373 \mathrm{~K}$ to $873 \mathrm{~K}$ at a ramping rate of $10 \mathrm{~K} / \mathrm{min}$ equipped with thermal couple detector (TCD). In-situ pyridine adsorption test was used to discriminate the distribution of Brønsted and Lewis acid sites using a Thermo Nicolet 6700 Fourier transform infrared spectrometer. The samples were pressed into self-supporting wafers (diameter: $1.6 \mathrm{~cm}$, $18 \mathrm{mg}$ ). Prior to the adsorption, the samples were pre-treated at $723 \mathrm{~K}$ for 4 hours under vacuum $\left(10^{-6}\right.$ Torr $)$. Then 1 Torr of pyridine was adsorbed at room temperature to reach the equilibrium. Afterwards, the samples were evacuated at 423, 573 and $723 \mathrm{~K}$ and the spectra were collected. The molar extinction coefficients for Brønsted (B) and Lewis (L) acid sites were taken from Ref. [40]. 


\subsection{Catalytic test}

The three samples (granules with diameter of 20-40 mesh) were tested in cumene cracking reaction conducted at atmospheric pressure in a downstream stainless steel fixed bed reactor $(10 \mathrm{~mm}$ internal diameter). The flow scheme of the reactor used for the cumene cracking is shown in Scheme 2. Prior to the reaction, the samples were purged under a flow of nitrogen $\left(60 \mathrm{~mL} \mathrm{~min}^{-1}\right)$ at $623 \mathrm{~K}$ for $2 \mathrm{~h}$. The reaction temperature and weight hourly space velocity were kept at $623 \mathrm{~K}$ and $2.5 \mathrm{~h}^{-1}$, respectively. The reactant and products were on-line analyzed by an Agilent 7890A gas chromatograph equipped with a $50 \mathrm{~m} \times 0.25 \mathrm{~mm} \times 0.5 \mu \mathrm{m}$ PC-PONA capillary column and a flame ionization detector. Cumene conversion was calculated as the amount of converted cumene divided by the amount of cumene in the feedstock. The coke amount on the catalysts after different reaction time was analyzed by an Elementar Vario EL III CHNS/O element analyzer.

\section{Results and Discussion}

\subsection{Phase analysis and textural properties of zeolite catalysts}

Wide and small angle XRD patterns, nitrogen adsorption-desorption isotherms, and representative TEM images of the three samples are presented in Figure 1. In the case of Sample-I, the XRD pattern characteristic of a pure MFI phase is measured. It should be noted that there is no diffraction peaks in the low range of $2-6^{\circ} 2$ Theta indicating the lack of ordered array of a mesostructure. In accordance with the XRD result, the nitrogen adsorption-desorption isotherm of Sample-I is a typical type I, indicating the exclusive presence of microporous structure. The Sample-I has BET surface area of 
$455 \mathrm{~m}^{2} / \mathrm{g}$, a total volume of $0.21 \mathrm{~cm}^{3} / \mathrm{g}$ and micropore volume of $0.17 \mathrm{~cm}^{3} / \mathrm{g}$ (Table 1). The typical TEM image reveals rectangular crystals with diameter of c.a. $3200 \mathrm{~nm} \times$ $1500 \mathrm{~nm}$. In contrast to the Sample-I, the XRD pattern of Sample-II does not contain any Bragg peaks in the range 5-60 ${ }^{\circ} 2$ Theta. However, a distinct peak at $2.2^{\circ} 2$ Theta indexed as (100) corresponding to ordered hexagonal mesostructured material is present. In addition, two peaks at 4.1 and $4.6^{\circ} 2$ Theta with hkl values of (110) and (200), respectively confirm the high order arrangement of the hexagonal mesopores. Nitrogen adsorption-desorption isotherm of Sample-II includes an $\mathrm{H} 1\left(p / p_{0}=0.35\right)$ and an $\mathrm{H} 4$ $\left(p / p_{0}>0.45\right)$ hysteresis loops typical for Type IV isotherm. These two hysteresis loops are attributed to the ordered Al-MCM-41 mesostructures. The paintbrush-like morphology of the MCM-41 material is shown in Figure 1. Besides, the FTIR spectrum of Sample-II contains an intense band at $534 \mathrm{~cm}^{-1}$ (Figure 2) which is an indication for the presence double five $(5-1)$ ring structure[41,42]. This is associated with the presence of secondary building units forming pentasil chains in the MFI framework. The band at $534 \mathrm{~cm}^{-1}$ is present in the FTIR spectra of both Sample-I and Sample-III (Figure 2). This result confirms that even though the ZSM-5 crystals collapsed after harsh alkali dissolution, some SBUs containing are preserved in the Sample-II [43]. Thus Sample-II can also be regarded as a suitable model of ordered mesoporous material consisting of MFI secondary building units. The XRD patterns of Sample-III and Sample-I are similar indicating the highly crystalline MFI zeolites. However, Sample-I and III have significantly different textural properties. The nitrogen adsorption-desorption isotherm of Sample-III is a 
mixture of type I and type IV, typical for hierarchical zeolite, represented by the rapid uptake at low relative pressures followed by nearly horizontal adsorption and desorption branches. The hysteresis loop at high relative pressure appears due to the formation of textural mesopores. Formation of such mesopores can be explained by the self-assembly of nanosized zeolite particles. However, no peaks in the small-angle XRD pattern of Sample-III appeared proving that no long range mesopores are formed. TEM image further reveals that Sample-III consists of ZSM-5 nanocrystals with size around $20 \mathrm{~nm}$. These nanocrystals are self-assembled in aggregates with a particle size of about $1 \mu \mathrm{m}$.

\subsection{Acidity analysis of zeolite catalysts}

Figure 3 shows $\mathrm{NH}_{3}$-TPD profiles of the three catalysts. All samples present a low temperature desorption peak at $473 \mathrm{~K}$ (L-peak) and a high temperature peak at $673 \mathrm{~K}$ (H-peak). L-peak is assigned to the weak interactions between the molecular sieves and ammonia molecules via hydrogen bonds $[44,45]$. On the other hand, the high temperature peak corresponds to strong acid sites present on the catalyst surface. The positions of the H-peaks at around $673 \mathrm{~K}$ are almost the same. Furthermore, it can be seen that in the case of Sample-I and Sample-III, clear maximum can be observed, while the peak in Sample-II is weak. Moreover, the peak area for the three samples is different, and the area decreases in the following order: Sample-I $>$ Sample-III > Sample-II. As the peak area is proportional to the amount of acid sites, the decrease in the acidic properties of the samples follows the same order. 
Furthermore, FT-IR spectroscopy study using pyridine as a probe molecule was performed to identify the differences in Brønsted and Lewis acid sites over the three catalysts (Figure 4). Bands at $1545 \mathrm{~cm}^{-1}$ and $1455 \mathrm{~cm}^{-1}$ are assigned to pyridine adsorbed on Brønsted acid sites (BAS) and Lewis acid sites (LAS), respectively. Quantitative analysis of coordinated pyridine species on the acidic sites are shown in Table S1. The results indicate that the amount of BAS decreases in the following order: Sample-I > Sample-III > Sample-II, whereas the amount of LAS follows the following order: Sample-II > Sample-I > Sample-III. Pyridine desorption at increasing temperatures leads to a decrease of the intensity of both bands and shows preferential desorption from Brønsted acid sites for all samples. Additionally, the BAS on Samples I and III are stable up to $573 \mathrm{~K}$, while the BAS on Sample-II is reduced significantly with the temperature increase. On the other hand Lewis acid sites are more stable upon temperature increase for all three samples. The ratio between BAS and LAS (B/L ratio) (Table S1) at $423 \mathrm{~K}$ shows that Sample 1 and III are primarily Brønsted acid catalysts whereas Sample-II is Lewis acid catalyst.

Distinctively different acidic properties are highly related to the different structural and textural features of the materials. Sample-I and III show strong IR band at c.a. 3610 $\mathrm{cm}^{-1}$ (Figure 5), assigned to the vibration of the bridged hydroxyl groups ( $\left.\mathrm{Si}-\mathrm{O}(\mathrm{H})-\mathrm{Al}\right)$. In the crystalline zeolitic materials these bridged $\mathrm{OH}$ groups are associated with the framework aluminum and the presence of Brønsted acid sites. On the contrary, this feature is not observed for Sample-II (Figure 5), while the pyridine adsorption spectrum clearly shows the presence of Brønsted acid sites (Figure 4). This ambiguity can be 
explained by the presence of extra framework aluminum in the vicinity of silanols that creates Brønsted acidity. Pseudo Brønsted acid sites generated by this mode are usually weaker in comparison to the BAS formed on the surface of highly crystalline zeolites $[46,47]$, as evidenced by the $\mathrm{NH}_{3}-\mathrm{TPD}$ and pyridine FTIR experiments.

\subsection{Cumene cracking on zeolite catalysts}

Cumene cracking is a standard test reaction used to assess the catalytic behavior of BAS[48]. During the reaction, cumene is first adsorbed and protonated on strong BAS, then converts into benzene and propylene, which are the main products of the cracking reaction. Afterwards, the formed propylene can further undergo hydrogen transfer reaction and form propane. Figure 6 presents the main results obtained for cumene cracking reaction performed at atmospheric pressure at $623 \mathrm{~K}$. During the initial stage of the reaction, Sample-I reaches the conversion of $98 \%$, and the ratio of propylene to propane is 1.9 . As the reaction proceeds (after $197 \mathrm{~min}$ ) the conversion decreases greatly to $56 \%$ with the propylene/propane ratio of 0.4 (Sample-I). After $463 \mathrm{~min}$ reaction time, the conversion is only $27 \%$, and the propylene becomes undetectable among the reaction products. The coke amount of Sample-I follows the trend opposite to cumene conversion as it increases gradually from $2.45 \%$ to $6.56 \%$ at $120 \mathrm{~min}$ and $463 \mathrm{~min}$, respectively.

In contrast to Sample-I, the cumene conversion of both Sample-II and Sample-III are much more stable within the tested time on stream. The cracking conversion of Sample-II is only $32 \%$ after $63 \mathrm{~min}$. Sample-III exhibits conversion of $97 \%$ at $63 \mathrm{~min}$ comparable to that of Sample-I, but still maintains high conversion even after $463 \mathrm{~min}$ 
(92\%). In agreement with the conversion change, the propylene to propane ratios of Sample-II and Sample-III generally are also more stable. Between 63 min and $463 \mathrm{~min}$, the propylene can hardly be detected among the products for Sample-II, whereas the propylene to propane ratio of Sample-III changes negligibly from 2.6 to 2.1.

At the initial stage of the reaction high cumene conversion of Samples I and III reflect their high amount of strong BAS. Ample amount of strong BAS also guarantees that the rate of cumene cracking conversion is much higher than that of hydrogen transfer. As a consequence the relative amount of propylene, which is presented as propylene to propane ratio (Figure 6, B), can maintain rather high level. On the other hand, due to the amorphous nature and weak acidity of Sample-II, the cumene conversion is quite low. Additionally, the rate of hydrogen transfer is comparable to the rate of cumene cracking, making the propylene content in the product extremely low.

Beside the high initial cracking conversion, the strong BAS are also responsible for the fast formation of coke precursors. In the cracking of cumene, carbenium ions are believed to be formed on the Brønsted acid sites. The stronger BAS are, it is more difficult for the carbenium ions to desorb and they have high possibility to condense further and form large coke precursors. The pores of the MFI zeolite are narrow in comparison to the kinetic diameters of the aromatic coke species $[12,49]$. These chemical species experience severe diffusion limitations and can easily block the zeolite pores. When the coking reaction reaches a point where whole parts of the active sites are completely blocked by the coke, these active sites are considered to be de facto "dead" [50]. With the further accumulation of the coke, cumene cracking conversion 
gradually decreases to the point comparable or even lower to hydrogen transfer reaction, making persistent decline of the propylene/propane ratio as seen in the case of Sample-1 (Figure 6). However, in the case of Sample-III with a shortened pathlength, aromatics may pass through the connected micro- and meso- pores, thus the BAS are easily restored and high cracking activity is maintained.

\subsection{Discussion on the distinctive functions of two types of hierarchical zeolite}

\section{structures}

Although the lifetime of both Sample-II and Sample-III are extended via soothing diffusion limitations of coke species within the MFI framework, cracking reaction performances of these two samples are quite different.

Sample-II, as a representative for raising the effective diffusion coefficient, is consisting of ordered mesoporous material with zeotype SBUs (short-range micropores ordering). All active sites are easily accessible for cumene molecules. However, this no strong acid sites are formed in the pore walls of the mesoporous materials that lead to poor cracking activity. Even though the strength and amount of the BAS can be improved by some methods such as partial crystallization [27] or nanocrystals assembly [28], the acid site properties still are not comparable with the zeolitic BAS. Sample-III, as a representative of reduced diffusion path, is consisting of self-assembled nanosized ZSM-5 zeolite crystals. This sample has high crystallinity and the active sites have the same nature and strength as the classical micronsized zeolite. While the diffusion path of the reactants and products become much shorter, thus leading to a substantial increase of the catalyst effectiveness factor. Since the 
bulky coke precursors leave the active sites easier, thus high cumene cracking conversion for a long time on stream is maintained.

Therefore in terms of improving the lifespan of zeolite catalysts via increasing catalyst effectiveness factor, the synthesis methods for reducing diffusion length are superior to the methods for raising the effective diffusion coefficient. Nevertheless, it is should also be noticed that the poor catalytic cracking with Sample-II is due to the mesopore walls amorphous nature. Methods for raising the effective diffusion coefficient of ZSM-5 with single-unit-cell nanosheets structure by Ryoo et al. [32] and self-pillared ZSM-5 nanosheets by Tsapatsis et al. [51] have been reported. The samples should also contain sufficient BAS to maintain high conversion of cumene cracking reactions for long time.

\section{Conclusions}

Two strategies for improving the catalyst effectiveness by raising the effective diffusivity or reducing the diffusion path length are presented. Removing diffusion limitations by utilizing the materials with much larger pores, such as Al-MCM-41, leads to the creation of weak pseudo-Brønsted acid sites that have inferior catalytic activities. On the contrary, utilizing self-assembled nanosized ZSM-5 leads to a high cracking activity accompanied by slower deactivation. It can be concluded that constructing hierarchical zeolitic structures with a short pathways for reactants and products is a good prospective to improve the catalyst effectiveness in diffusion controlled reactions. The mesopores offer improved accessibility of larger molecules, 
whereas active sites located inside the micropores control the catalytic performance of the materials.

\section{References}

[1] J. Cejka, H. Van Bekkum, A. Corma, F. Schueth, Introduction to zeolite molecular sieves, Elsevier, 2007.

[2] C. Martínez, A. Corma, Inorganic molecular sieves: Preparation, modification and industrial application in catalytic processes, Coord. Chem. Rev. 255 (2011) $1558-1580$.

[3] P.B. Weisz, V.J. Frilette, Intracrystalline and molecular-shape-selective catalysis by zeolite salts, J. Phys. Chem. 64 (1960) 382.

[4] V.J. Frilette, P.B. Weisz, R.L. Golden, Catalysis by Crystalline Aluminosilicates I. Cracking of Hydrocarbon Types over Sodium and Calcium "X" Zeolites, J. Catal. 1 (1962) 301-306.

[5] P.B. Weisz, V.J. Frilette, R.W. Maatman, E.B. Mower, Catalysis by Crystalline Aluminosilicates II. Molecular-Shape Selective Reactions, J. Catal. 1 (1962) $307-312$.

[6] R.A. Meyers, ed., Handbook of Pertoleum Refining Processes, 3rd ed., McGraw-Hill Education, New York, 2004.

[7] J.-P. Gilson, W. Vermeiren, Impact of Zeolites on the Petroleum and Petrochemical Industry, Top. Catal. 52 (2009) 1131-1161. 
[8] T.C. Hoff, M.J. Holmes, J. Proano-Aviles, L. Emdadi, D. Liu, R.C. Brown, J.-P. Tessonnier, Decoupling the Role of External Mass Transfer and Intracrystalline Pore Diffusion on the Selectivity of HZSM-5 for the Catalytic Fast Pyrolysis of Biomass, ACS Sustain. Chem. Eng. 5 (2017) 8766-8776.

[9] O. Levenspiel, Chemical Reaction Engineering, 3rd ed., John Wiley \& Sons, Ltd., 1999.

[10] A. Primo, H. Garcia, Zeolites as catalysts in oil refining, Chem. Soc. Rev. 43 (2014) 7548-7561.

[11] C.H. Collett, J. McGregor, Things go better with coke: the beneficial role of carbonaceous deposits in heterogeneous catalysis, Catal. Sci. Technol. 6 (2016) 363-378.

[12] Z. Li, Y. Liu, X. Yang, Y. Xing, Z. Wang, Q. Yang, R.T. Yang, Desorption Kinetics of Naphthalene and Acenaphthene over Two Activated Carbons via Thermogravimetric Analysis, Energy \& Fuels. 29 (2015) 5303-5310.

[13] F. Ngoye, L. Lakiss, Z. Qin, S. Laforge, C. Canaff, M. Tarighi, V. Valtchev, K. Thomas, A. Vicente, J.P. Gilson, Y. Pouilloux, C. Fernandez, L. Pinard, Mitigating coking during methylcyclohexane transformation on HZSM-5 zeolites with additional porosity, J. Catal. 320 (2014) 118-126.

[14] J. Kim, M. Choi, R. Ryoo, Effect of mesoporosity against the deactivation of MFI zeolite catalyst during the methanol-to-hydrocarbon conversion process, J. Catal. 269 (2010) 219-228. 
[15] E.T.C. Vogt, B.M. Weckhuysen, Fluid catalytic cracking : recent developments on the grand old lady of zeolite catalysis, Chem. Soc. Rev. 44 (2015) $7342-7370$.

[16] K.A. Tarach, J. Martinez-triguero, F. Rey, K. Góra-marek, Hydrothermal stability and catalytic performance of desilicated highly siliceous zeolites ZSM-5, J. Catal. 339 (2016) 256-269.

[17] P. Peng, Y. Wang, M.J. Rood, Z. Zhang, F. Subhan, Z. Yan, L. Qin, Z. Zhang, Z. Zhang, X. Gao, Effects of dissolution alkalinity and self-assembly on ZSM-5-based micro-/mesoporous composites: a study of the relationship between porosity, acidity, and catalytic performance, CrystEngComm. 17 (2015) $3820-3828$.

[18] X. Dong, S. Shaikh, J.R. Vittenet, J. Wang, Z. Liu, K.D. Bhatte, O. Ali, W. Xu, I. Osorio, Y. Saih, others, Fine Tuning the Diffusion Length in Hierarchical ZSM-5 to Maximize the Yield of Propylene in Catalytic Cracking of Hydrocarbons, ACS Sustain. Chem. Eng. 6 (2018) 15832-15840.

[19] O. Awayssa, N. Al-Yassir, A. Aitani, S. Al-Khattaf, Modified HZSM-5 as FCC additive for enhancing light olefins yield from catalytic cracking of VGO, Appl. Catal. A Gen. 477 (2014) 172-183.

[20] N. Masoumifard, R. Guillet-Nicolas, F. Kleitz, Synthesis of Engineered Zeolitic Materials: From Classical Zeolites to Hierarchical Core-Shell Materials, Adv. Mater. 30 (2018) 1704439. 
[21] K. Möller, T. Bein, Mesoporosity-a new dimension for zeolites, Chem. Soc. Rev. 42 (2013) 3689-3707.

[22] X. Chang, L. He, H. Liang, X. Liu, Z. Yan, Screening of optimum condition for combined modification of ultra-stable Y zeolites using multi-hydroxyl carboxylic acid and phosphate, Catal. Today. 158 (2010) 198-204.

[23] Z. Qin, K.A. Cychosz, G. Melinte, H. El Siblani, J.-P. Gilson, M. Thommes, C. Fernandez, S. Mintova, O. Ersen, V. Valtchev, Opening the Cages of Faujasite-Type Zeolite, J. Am. Chem. Soc. 139 (2017) 17273-17276.

[24] D. Verboekend, J. Pérez-Ramírez, Design of hierarchical zeolite catalysts by desilication, Catal. Sci. Technol. 1 (2011) 879-890.

[25] E.-P. Ng, D. Chateigner, T. Bein, V. Valtchev, S. Mintova, Capturing ultrasmall EMT zeolite from template-free systems, Science. 335 (2012) 70-73.

[26] H. Awala, J.-P. Gilson, R. Retoux, P. Boullay, J.-M. Goupil, V. Valtchev, S. Mintova, Template-free nanosized faujasite-type zeolites, Nat. Mater. 14 (2015) 447.

[27] D.T. On, S. Kaliaguine, Ultrastable and Highly Acidic, Zeolite-Coated, Angew. Chem. Int. Ed. 41 (2002) 1036-1040.

[28] Y. Liu, W. Zhang, T.J. Pinnavaia, Steam-Stable MSU-S Aluminosilicate Mesostructures Assembled from Zeolite ZSM-5 and Zeolite Beta Seeds , Angew. Chem. Int. Ed. 40 (2001) 1255-1258. 
[29] A. Corma, V. Fornés, J.M. Guil, S. Pergher, T.L.M. Maesen, J.G. Buglass, Preparation, characterisation and catalytic activity of ITQ-2, a delaminated zeolite, Micropor. Mesopor. Mater. 38 (2000) 301-309.

[30] A.H. Janssen, I. Schmidt, C.J.H. Jacobsen, A.J. Koster, K.P. de Jong, Exploratory study of mesopore templating with carbon during zeolite synthesis, Micropor. Mesopor. Mater. 65 (2003) 59-75.

[31] M. Choi, H.S. Cho, R. Srivastava, C. Venkatesan, D.-H. Choi, R. Ryoo, Amphiphilic organosilane-directed synthesis of crystalline zeolite with tunable mesoporosity, Nat. Mater. 5 (2006) 718-723.

[32] M. Choi, K. Na, J. Kim, Y. Sakamoto, O. Terasaki, R. Ryoo, Stable single-unit-cell nanosheets of zeolite MFI as active and long-lived catalysts, Nature 461 (2009) 246-249.

[33] J. Wang, J.C. Groen, W. Yue, W. Zhou, M.-O. Coppens, Single-template synthesis of zeolite ZSM-5 composites with tunable mesoporosity, Chem. Commun. (2007) 4653-4655.

[34] P. Peng, Y. Wang, Z. Zhang, K. Qiao, X. Liu, Z. Yan, F. Subhan, S. Komarneni, ZSM-5-based mesostructures by combined alkali dissolution and re-assembly: Process controlling and scale-up, Chem. Eng. J. 302 (2016) 323-333.

[35] I.I. Ivanova, E.E. Knyazeva, Micro-mesoporous materials obtained by zeolite recrystallization: synthesis, characterization and catalytic applications, Chem. Soc. Rev. 42 (2013) 3671-3688. 
[36] J. García-Martínez, K. Li, G. Krishnaiah, A mesostructured Y zeolite as a superior FCC catalyst - from lab to refinery, Chem. Commun. 48 (2012) $11841-11843$.

[37] J. Pérez-Ramírez, C.H. Christensen, K. Egeblad, C.H. Christensen, J.C. Groen, Hierarchical zeolites: enhanced utilisation of microporous crystals in catalysis by advances in materials design, Chem. Soc. Rev. 37 (2008) 2530.

[38] Z. Zhang, Z. Yan, Highly hydrothermally stable Al-MCM-41 with accessible void defects, J. Porous Mater. 20 (2013) 309-317.

[39] C.-M. Song, J. Jiang, Z.-F. Yan, Synthesis and characterization of MCM-41-type composite materials prepared from ZSM-5 zeolite, J. Porous Mater. 15 (2008) 205-211.

[40] C.A. Emeis, Determination of integrated molar extinction coefficients for infrared absorption bands of pyridine adsorbed on solid acid catalysts, J. Catal. 141 (1993) 347-354.

[41] J.C. Jansen, F.J. van der Gaag, H. van Bekkum, Identification of ZSM-type and other 5-ring containing zeolites by i.r. spectroscopy, Zeolites. 4 (1984) 369-372.

[42] D.B. Shukla, V.P. Pandya, Estimation of crystalline phase in ZSM-5 zeolites by infrared spectroscopy, J. Chem. Technol. Biotechnol. 44 (1989) 147-154.

[43] H. Wang, Y. Liu, T.J. Pinnavaia, Highly Acidic Mesostructured Aluminosilicates Assembled from Surfactant-Mediated Zeolite Hydrolysis Products, J. Phys. Chem. B. 110 (2006) 4524-4526. 
[44] M. Niwa, N. Katada, New Method for the Temperature-Programmed Desorption (TPD) of Ammonia Experiment for Characterization of Zeolite Acidity: A Review, Chem. Rec. 13 (2013) 432-455.

[45] N. Katada, H. Igi, J.-H. Kim, M. Niwa, Determination of the acidic properties of zeolite by theoretical analysis of temperature-programmed desorption of ammonia based on adsorption equilibrium, J. Phys. Chem. B. 101 (1997) $5969-5977$.

[46] E.J.M. Hensen, D.G. Poduval, V. Degirmenci, D.A.J.M. Ligthart, W. Chen, F. Maugé, M.S. Rigutto, J.A.R. van Veen, Acidity Characterization of Amorphous Silica-Alumina, J. Phys. Chem. C. 116 (2012) 21416-21429.

[47] K. Larmier, C. Chizallet, S. Maury, N. Cadran, J. Abboud, A.-F. Lamic-Humblot, E. Marceau, H. Lauron-Pernot, Isopropanol Dehydration on Amorphous Silica-Alumina: Synergy of Brønsted and Lewis Acidities at Pseudo-Bridging Silanols, Angew. Chem. Int. Ed. 56 (2017) 230-234.

[48] A. Corma, B.W. Wojciechowski, The catalytic cracking of cumene, Catal. Rev. Sci. Eng. 24 (1982) 1-65.

[49] D. Laprune, C. Theodoridi, A. Tuel, D. Farrusseng, F.C. Meunier, Environmental Effect of polyaromatic tars on the activity for methane steam reforming of nickel particles embedded in silicalite-1, Appl. Catal. B Environ. 204 (2017) 515-524. 
[50] D. Cai, Y. Ma, Y. Hou, Y. Cui, Z. Jia, C. Zhang, Y. Wang, F. Wei, Establishing a discrete Ising model for zeolite deactivation: inspiration from the game of Go, Catal. Sci. Technol. 7 (2017) 2440-2444.

[51] X. Zhang, D. Liu, D. Xu, S. Asahina, K.A. Cychosz, K.V. Agrawal, Y. Al Wahedi, A. Bhan, S. Al Hashimi, O. Terasaki, M. Thommes, M. Tsapatsis, Synthesis of Self-Pillared Zeolite Nanosheets by Repetitive Branching, Science. 336 (2012) 1684-1687.

\section{Acknowledgement}

PP gratefully acknowledged the China Scholarship Council (CSC201706450035) and K. C. Wong Education Foundation for their financial support and the authors gratefully acknowledged funding from Thousand Talents Program for Foreign Experts (WQ20152100284). 
Thiele Modulus

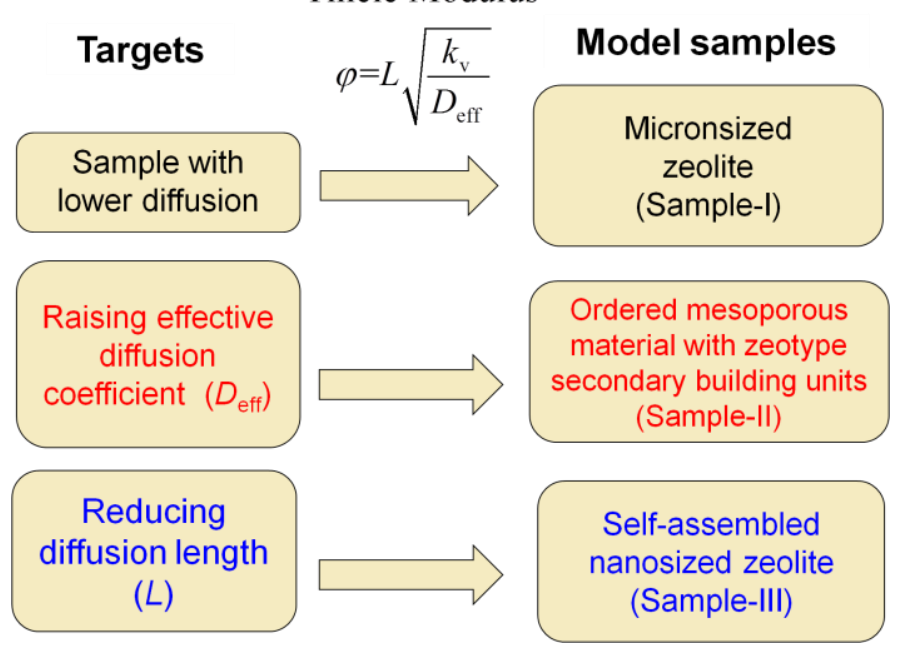

Scheme 1. Strategies toward preparation of model samples with enhanced catalyst effectiveness. 


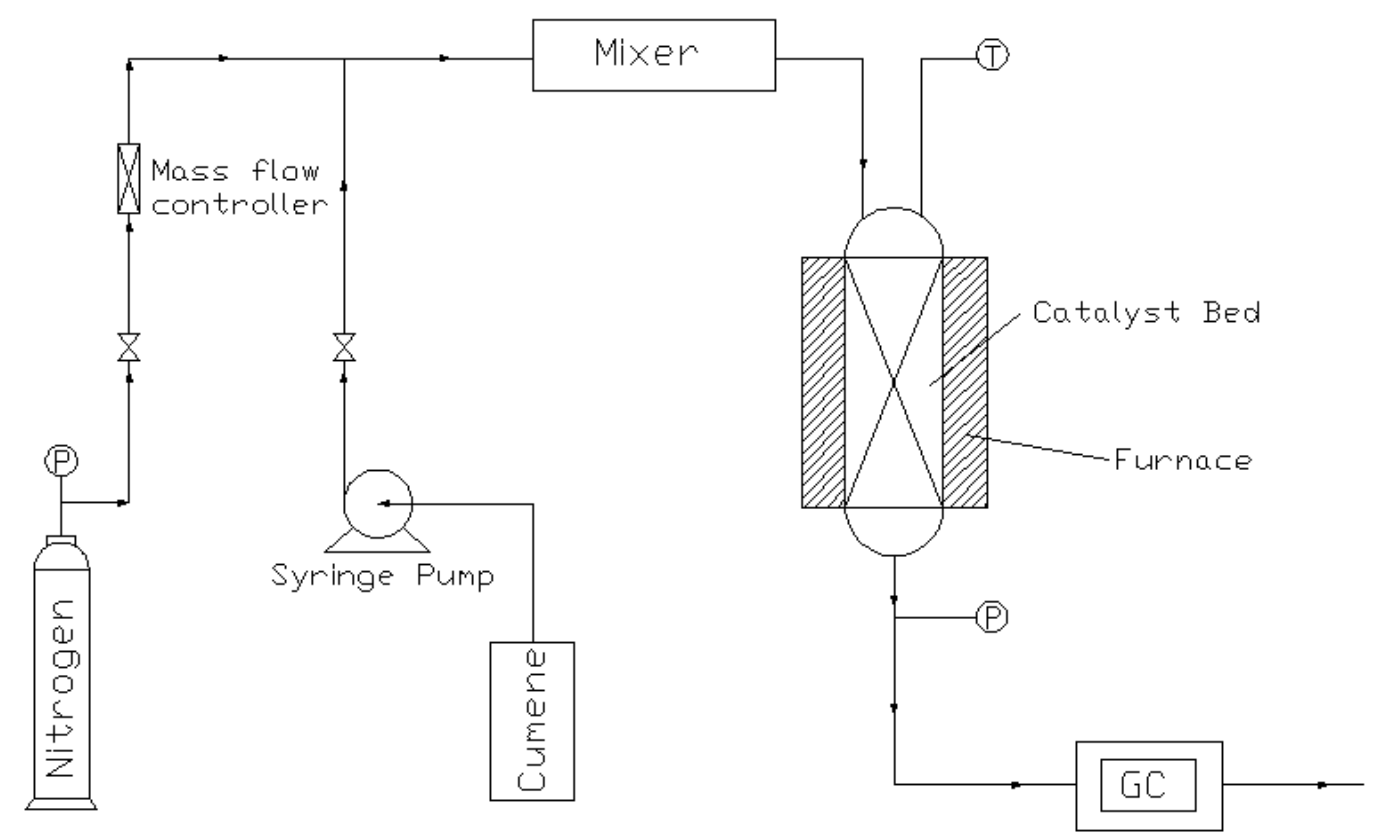

Scheme 2. Flow scheme of the fixed bed reactor used the cumene cracking 

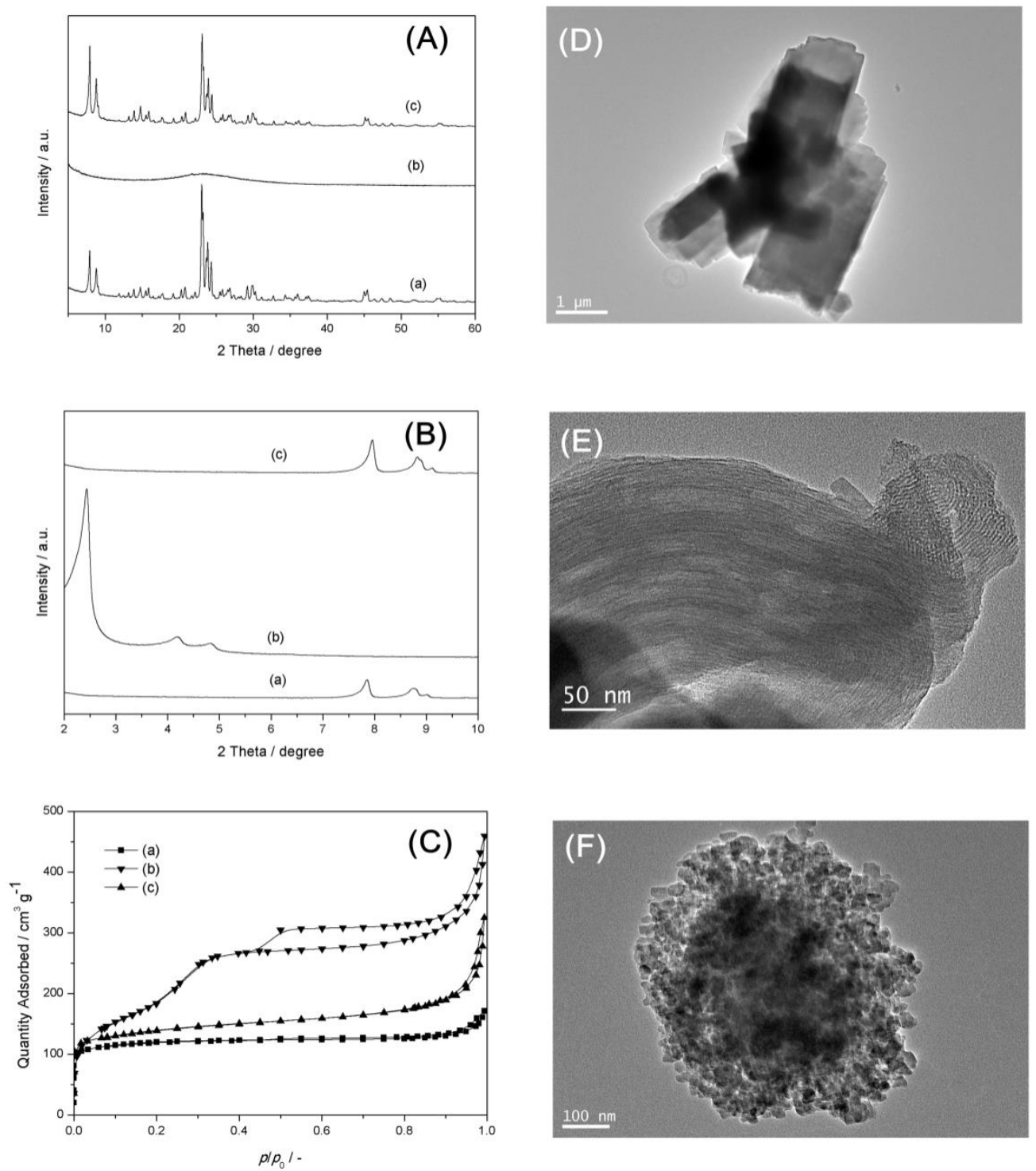

Figure 1. Wide-angle XRD patterns (A), small-angle XRD patterns (B), nitrogen adsorption-desorption isotherms (C) of Sample-I: micronsized ZSM-5 (a), Sample-II: ordered mesoporous material with zeotype secondary building units (b) and Sample-III: self-assembled nanosized ZSM-5 (c); TEM images of Sample-I (D) Sample-II (E), and Sample-III (F). 


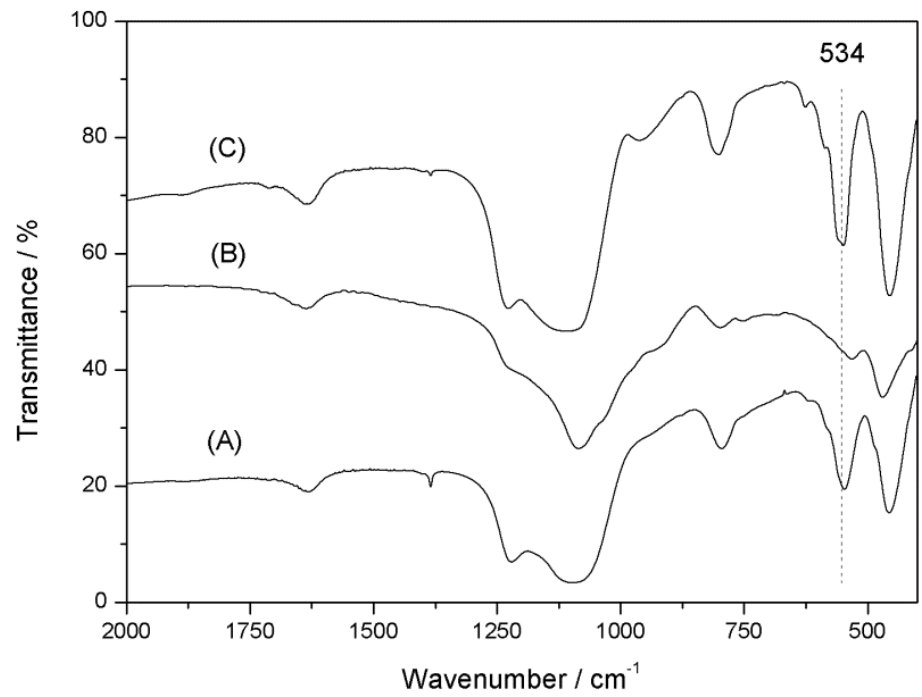

Figure 2. FTIR spectra of Sample-I: micronsized ZSM-5 (A), Sample-II: ordered mesoporous material with zeotype secondary building units (B) and Sample-III: self-assembled nanosized ZSM-5 (C) 


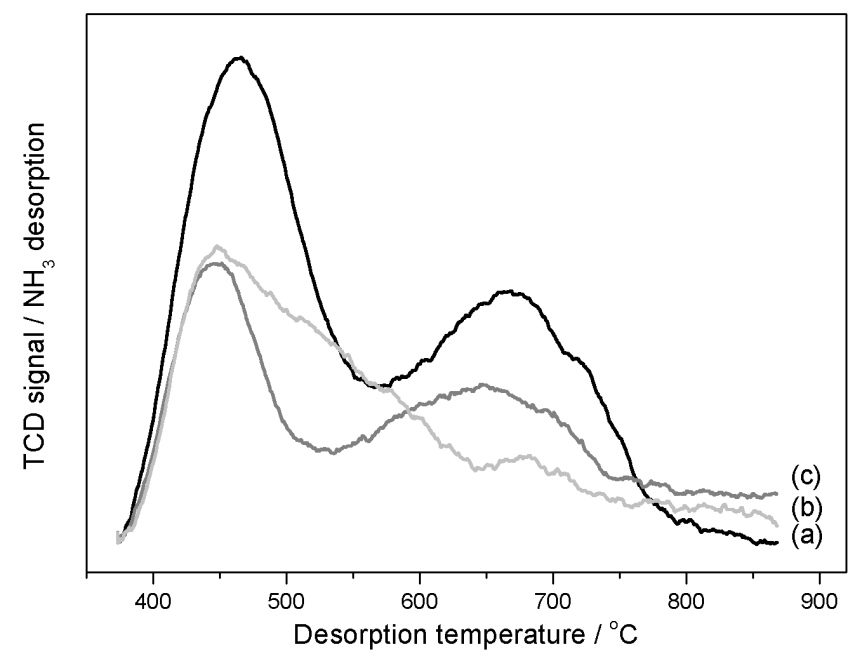

Figure 3. Ammonia temperature programmed desorption patterns of Sample-I: micronsized ZSM-5 (A), Sample-II: ordered mesoporous material with zeotype secondary building units (B) and Sample-III: self-assembled nanosized ZSM-5 (C). 
(A)

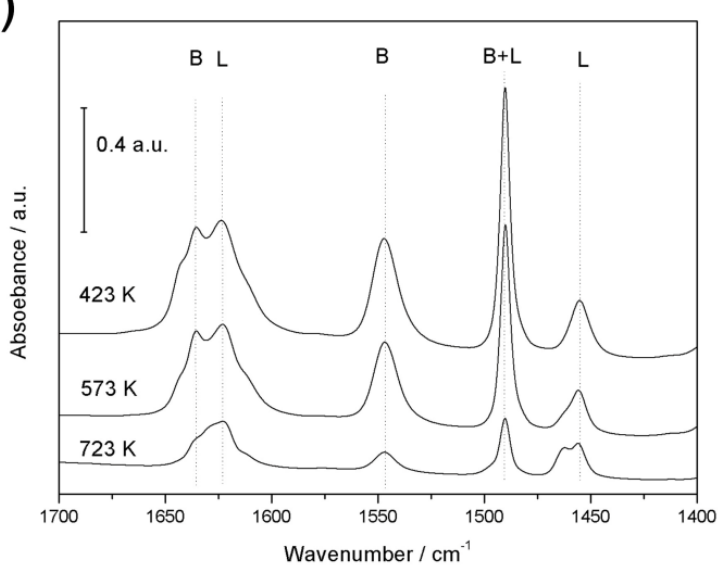

(B)

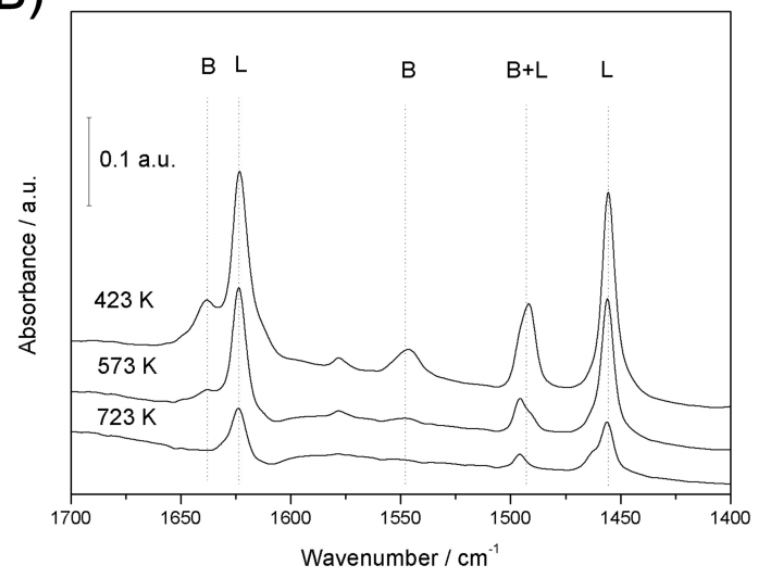

(C)

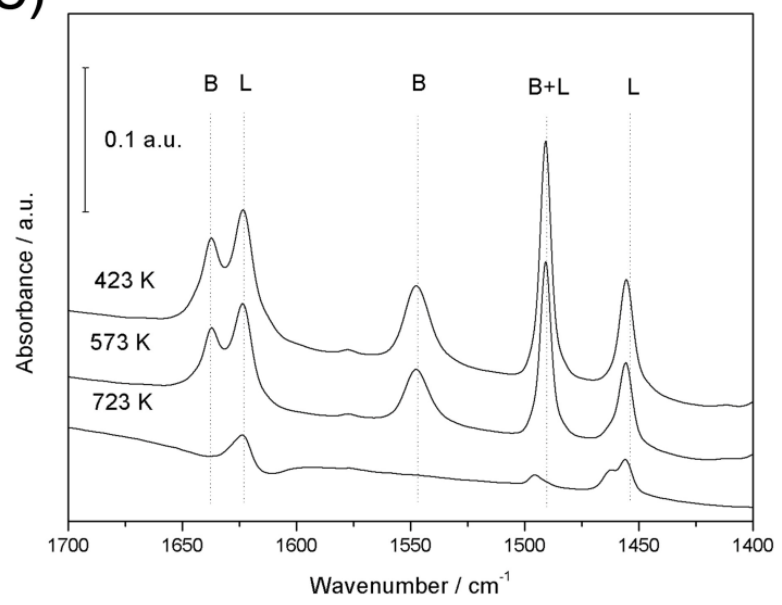

Figure 4 FTIR spectra of Sample-I: micronsized ZSM-5 (A), Sample-II: ordered mesoporous material with zeotype secondary building units (B) and Sample-III: self-assembled nanosized ZSM-5 (C) using pyridine as a probe molecule collected at 423, 573 and $723 \mathrm{~K}$. 


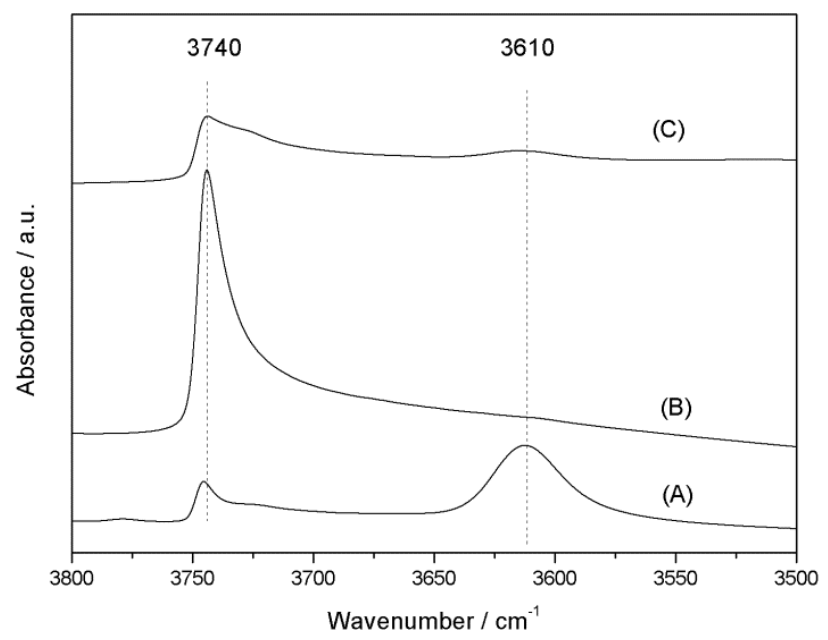

Figure 5 FTIR spectra of Sample-I: micronsized ZSM-5 (A), Sample-II: ordered mesoporous material with zeotype secondary building units (B) and Sample-III: self-assembled nanosized ZSM-5 (C) in the hydroxyl group region of $3500-3800 \mathrm{~cm}^{-1}$. 
(A)

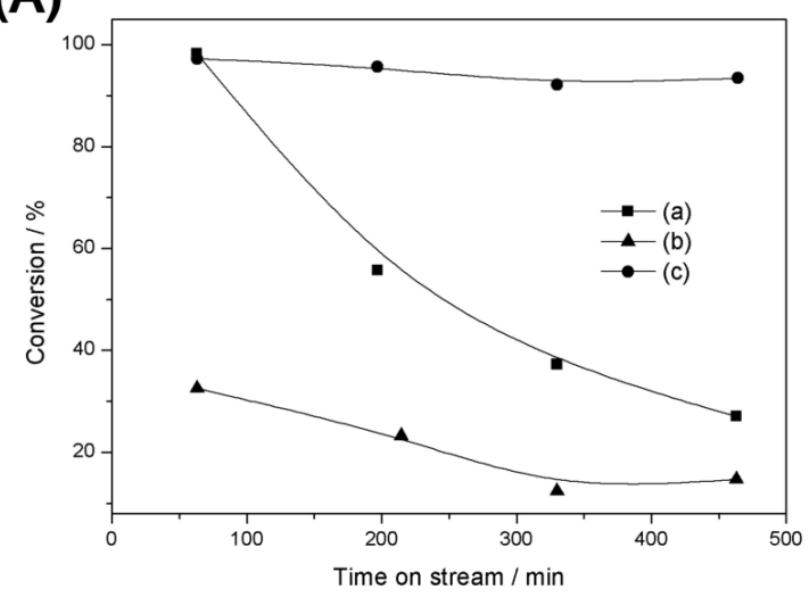

(B)

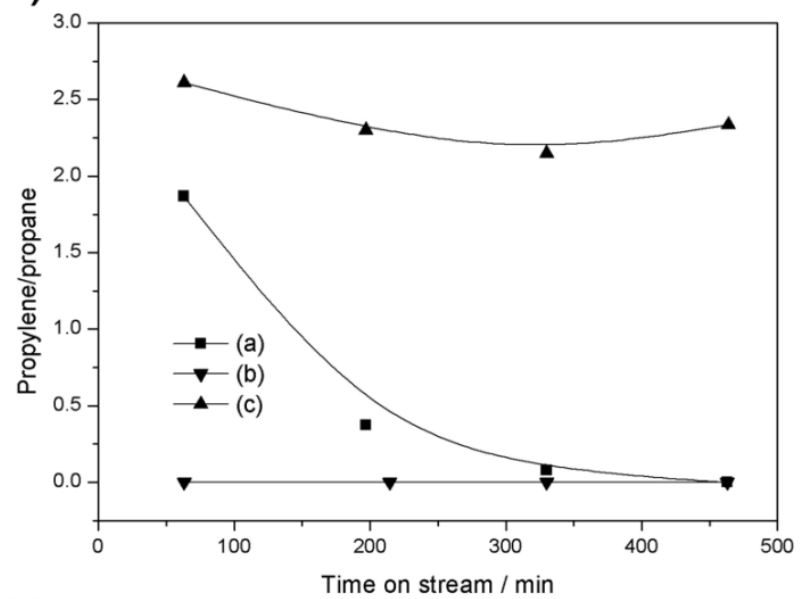

(C)

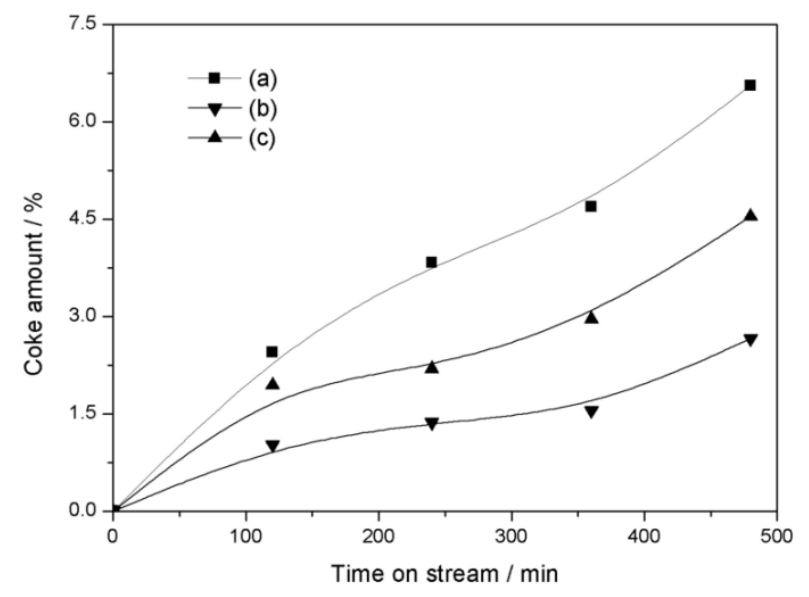

Figure 6 Conversion (A), propylene to propane ratio (B), and coke content (C), as a function of time on stream of Sample-I: micronsized ZSM-5 (a), Sample-II: ordered mesoporous material with zeotype secondary building units (b) and Sample-III: self-assembled nanosized ZSM-5 (c) in cumene cracking reaction. 
Table 1 Textural properties of Sample-I: micronsized ZSM-5, Sample-II: ordered mesoporous material with zeotype secondary building units, and Sample-III: self-assembled nanosized ZSM-5.

\begin{tabular}{c|ccc}
\hline & $\begin{array}{c}S_{\text {BET }} / \\
\left(\mathrm{m}^{2} / \mathrm{g}\right)\end{array}$ & $\begin{array}{c}V_{\text {total }} / \\
\left(\mathrm{cm}^{3} / \mathrm{g}\right)\end{array}$ & $\begin{array}{c}V_{\text {micro }} / \\
\left(\mathrm{cm}^{3} / \mathrm{g}\right)\end{array}$ \\
\hline Sample-I & 455 & 0.21 & 0.17 \\
Sample-II & 763 & 0.53 & 0.01 \\
Sample-III & 516 & 0.33 & 0.17 \\
\hline
\end{tabular}

